\title{
La emergencia de la economía híbrida como modelo de producción de contenidos en internet. El ejemplo de ninremixes.com
}

\author{
María Vanessa GARCÍA GUARDIA \\ Universidad Complutense de Madrid \\ vansgg_76@yahoo.es \\ Rafael Timón Gómez \\ Universidad Complutense de Madrid \\ rafaeltimongomez@gmail.com
}

\begin{abstract}
Resumen:
La cultura generada dentro de lo que se ha venido a llamar economía de compartición, centra parte del debate acerca del futuro de la difusión del conocimiento y de las industrias culturales en la era digital. Este artículo analiza, desde una perspectiva multidisciplinar, algunos aspectos económicos, comunicativos y legales esenciales en la propuesta del activista de internet Lawrence Lessig acerca de un modelo híbrido, que combina elementos del intercambio comercial usual de bienes culturales y de esa economía de compartición, a través del estudio de un ejemplo concreto de híbrido, la página web de remezclas ninremixes.com
\end{abstract}

Palabras clave: Economía híbrida; cooperación; remezcla; cultura.

The emergence of hybrid economy as production model of contents in the internet. The ninremixes.com example.

\begin{abstract}
:
The culture generated within what has come to be known as the sharing economy focuses part of its debate on the future of the dissemination of knowledge and cultural industries in the digital era. This paper analyses from a multidisciplinary perspective, through the study of a specific hybrid example the remix website ninremixes.com, several economic, communicative and legal aspects fundamental to internet activist Lawrence Lessig's proposal for a hybrid model, combining elements of the usual commercial trade of cultural property and that sharing economy.
\end{abstract}

Key Words: Hibrid economy; cooperation; remix; culture.

\section{Referencia normalizada:}

García Guardia, M. V. y Timón Gómez, R. (2014): La emergencia de la economía híbrida como modelo de producción de contenidos en internet. El ejemplo de ninremixes.com. Historia y Comunicación Social. Vol. 19. Núm. Especial Febrero. Págs. 439-450.

Sumario:_1. Introducción. 2. Metodología. 3. Economía comercial y economía de compartición. 4. La economía de compartición en internet. 5. Economía híbrida. 


\section{Introducción}

A finales de dos mil ocho, Lawrence Lessig publicó Remix ${ }^{1}$. En esa obra, Lessig, conocido por ser el fundador de la organización Creative Commons, propone un modelo de puesta a disposición de contenidos en internet que considera dominará la arquitectura del comercio en la red. Es lo que denomina un modelo de economía híbrida, que combina elementos de la economía comercial y de la de compartición. Este modelo no es especulativo, sino que describe la forma en que estaban actuando varias compañías en internet sobre la base de la cooperación, asumiendo las posibilidades que proporciona la Web 2.0, para generar y comunicar información y conocimiento. Dos mil doce vio la edición en castellano de esta obra, y como esa construcción, por su vigencia, pero también por su complejidad, merece una atención detallada.

La propuesta de Lessig se enmarca dentro de un movimiento más amplio, conocido como cultura libre, que en su traslación del software a los productos culturales se ha venido encontrando con problemas para consolidar un modelo sólido para el desarrollo de estos y el sostenimiento económico de sus productores.

El software libre ha demostrado sobradamente su capacidad para llegar a soluciones técnicas fiables partiendo de la base de los dos principios esenciales que lo guían: la libertad (para usarlo, copiarlo, distribuirlo y modificarlo), y la cooperación (puesto que las modificaciones que se realicen en él han de ser libres también, todo aquel que lo modifica está contribuyendo a aportar soluciones o a abordar nuevas utilidades de las que la sociedad puede beneficiarse), y es un hecho que se están utilizando programas libres en multitud de aparatos electrónicos, lo que incentiva la cooperación entre los desarrolladores y permite que se creen modelos de negocio basados en la prestación de servicios en torno al software.

Pero el software es, obviamente, lo que podríamos llamar un nativo tecnológico, un producto digital fácil de liberar y compartir. No así otros productos culturales a los que estos principios se quieren extender: las producciones audiovisuales, musicales, literarias y artísticas. Éstas, por naturaleza y tradición, son más difíciles de liberalizar y de insertar en un proceso dialógico de desarrollo cooperativo como el del software libre.

\section{Metodología}

En la presente investigación analizaremos el modelo de economía híbrida de Lessig a través del estudio de un supuesto real que responde a esa tipología, la página web www.ninremixes.com, en la que el músico Trent Reznor comparte, para su libre utilización y remezcla, varias de sus canciones. De esta manera, utilizaremos una metodología descriptiva dentro de un estudio causal comparativo, para conocer el funcionamiento de los objetos de estudio, clarificar los procesos que supone ese 
modelo híbrido, y confrontar sus semejanzas y diferencias con aquellas prácticas que sólo atienden a uno de los tipos económicos hibridados, con el fin de determinar si la aportación de Lessig brinda parámetros para superar los problemas antes mencionados.

\section{Economía comercial y economía de compartición}

Para entender el planteamiento de Lessig, debemos partir de su concepción de economía. Un planteamiento sencillo y no especialmente original, pero que nos ayudará a situarnos mejor en el presente análisis, ya que, muchas veces, la economía es la gran olvidada cuando las ciencias sociales se aplican a la comunicación. Así, Lessig entiende por economía "una práctica de intercambio que se sostiene a si misma, o es sostenida, a lo largo del tiempo" (2012: 154). En seguida, Lessig, distingue entre dos tipos de economía: comercial y de compartición. Respecto de la economía comercial, asume la definición de Yokai Benkler (2004: 273-358) y comprende que es aquella en que el mencionado intercambio se define en términos de precio. Es decir, en la que los bienes, materiales o inmateriales (servicios), se intercambian por dinero, y el precio determina la cantidad de dinero que se considera como contraprestación por ese bien. Sin embargo, en la economía de compartición el intercambio vendrá regulado por un complejo sistema de relaciones sociales, para Lessig, todavía difícil de discernir (2012: 181). De esta forma, la economía de compartición es economía porque implica un conjunto de prácticas de intercambio, pero son las relaciones sociales las que cumplen el papel del dinero: determinar el valor de los recursos. Así, una persona que actúa dentro de una economía de compartición, ofrece ese recurso porque existen lazos sociales o afectivos que le unen, o que quiere que le unan, con la persona o grupo de personas a las que se lo ofrece. Intentar explicar de que manera funcionan estas prácticas en un caso concreto, bajo que criterios actúan las partes implicadas, y como funcionan sus procesos comunicacionales, será, por lo tanto, el objetivo de este estudio.

\section{La economía de compartición en internet}

Tanto la economía comercial como la de compartición se han visto impulsadas por la aparición de internet. Pero ha sido ésta última la que ha sufrido una proyección más interesante, puesto que las nuevas tecnologías han facilitado que las redes sociales, usualmente domésticas y locales, en las que se asentaba tradicionalmente la economía de compartición, hayan encontrado proyección potencialmente mundial, zafándose de la necesidad de cercanía geográfica y social, para poder constituirse por personas de cualquier parte del mundo y sin límite aparente establecido por la condición social, que voluntariamente entablan relaciones sociales basadas en la coincidencia en torno a uno o varios intereses comunes. Así, la economía de compartición 
en internet se asienta en relaciones del mismo tipo que las que suponen la base de la economía de compartición tradicional, por lo que, al igual que en ésta, participar de relaciones sociales de este tipo, pertenecer, por tanto, a una comunidad, supondrá, siempre, aceptar las normas que rigen las relaciones entre sus miembros.

Un ejemplo paradigmático, que nos puede ayudar a entender de que estamos hablando, es el de Wikipedia. Esta enciclopedia online se construye mediante la participación voluntaria y no remunerada monetariamente, de todo aquel que esté dispuesto a escribir o corregir alguna de sus entradas. Así, es interesante analizar como ha logrado desarrollar un proyecto tan sólido sin que medien recompensas económicas para sus colaboradores.

Una de las claves de la consolidación de Wikipedia es su gratuidad, pero los usuarios que la consultan buscarán, también, veracidad en la información que proporciona. Así, si se ha convertido en una referencia básica en ese sentido, es porque la veracidad de la información que contiene es, por lo menos, comparable a la de otras enciclopedias. De esta forma, cabe preguntarse, cómo es posible que una enciclopedia redactada por personas anónimas, cuya autoridad acerca del tema sobre el que escriben no está contrastada, ni se quiere contrastar, pueda generar información válida, sobre todo, si tenemos en cuenta que se trata de una comunidad que se rige por normas laxas, es decir, sin sanciones respaldadas por la fuerza de un poder constituido oficialmente, ni penalizaciones económicas, a modo de un trasunto de lo que se conoce como soft law. Una posible respuesta, implicaría asumir que las economías de compartición se rigen por una racionalidad interna que, mayoritariamente, es asumida por aquellos que participan en ellas, puesto que, si los participantes no asumen las premisas que implica esa racionalidad, la comunicación entre ellos, el entendimiento, no es posible, y sin comunicación las relaciones sociales que sustentan esa comunidad dejarían de tener sentido, destruyendo la propia comunidad. No estaríamos ante la asunción explícita y voluntaria de un sistema normativo, sino de un planteamiento cercano a las bases sobre las que se asienta la teoría de la acción comunicativa desarrollada por Jurgen Habermas². Éste entiende por acción comunicativa "aquellas manifestaciones simbólicas (lingüísticas y no lingüísticas) con que los sujetos capaces de lenguaje y acción entablan relaciones con la intención de entenderse sobre algo y coordinar así sus actividades" (1988: 453), por lo que considera que los sujetos se manifiestan de una determinada manera en el desarrollo de sus actos comunicativos, y esa manera se estructura en una racionalidad concreta -comunicativa-, intrínseca a la necesidad de comunicación. Para Habermas, la acción comunicativa y el discurso, en los casos en que la comunicación presenta problemas, son condiciones esenciales para el entendimiento y, así, para la cohesión social. Habermas no atiende al estatus ontológico de esa racionalidad, sólo argumenta que de los actos comunicativos que se dan entre las personas se puede extraer los criterios implícitos de la racionalidad que los guía (Carabante, 2011: 207-210). De esta forma, si trasladamos esta macro teoría a una comunidad concreta, en este caso, Wikipedia, podemos ver que del comportamiento de los participantes activos en la comunidad, se pueden extraer normas que regulan sus actos comunicativos dentro de esa comunidad, y que basculan, principalmente, 
alrededor de la pretensión que Habermas relaciona con aquellos actos comunicativos relacionados con la realidad exterior, la pretensión de verdad. Puesto que el objetivo de Wikipedia es compartir información veraz, aquellos que participan en la elaboración de la misma - que puede ser cualquiera que tenga la voluntad de hacerlo-, asientan sus relaciones sociales en torno a esa intención. Es decir, el interés común que une a la comunidad es generar información lo más objetiva posible (sin entrar en disquisiciones más profundas acerca de esa posibilidad). Esta premisa parece que es respetada, en gran medida, por aquellos voluntarios que alimentan la enciclopedia. Según su fundador, Jimmy Wales:

Resulta un poco sorprendente; tengo por seguro que si me hubieras preguntado antes de Wikipedia hasta que punto éste sería un gran problema, yo habría contestado: bueno, espero que no sea increíblemente sesgada sobre temas controvertidos. Espero que eso no ocurra. Pues resulta que no ocurre, que la comunidad es bastante buena (Lessig, 2012: 195).

Esto significa que es plausible asumir que, aunque no sea explícitamente, las personas que participan en el desarrollo de Wikipedia asumen los criterios de racionalidad comunicativa necesarios para que la comunidad funcione, y lo hacen, es decir, participan en la comunicación, buscan el entendimiento -y cuando éste no se logra, porque alguien rechaza la veracidad de la pretensión de otro, la comunidad, en términos habermasianos, puede recurrir, tiene los mecanismos, para exigir el desempeño discursivo de esa pretensión a través de la edición de contenido y las páginas de discusión-, porque esa comunidad les aporta valor, aunque éste no pueda traducirse en términos monetarios.

\section{Economía híbrida}

Cómo es fácil suponer, la economía híbrida será aquella que vincula el modelo de economía comercial con el de compartición, creando un nuevo sistema con peculiaridades propias, pero que, sin embargo, necesita mantener separados ambos sistemas para poder subsistir:

Si quienes colaboran en la economía de compartición comienzan a considerarse a si mismos como herramientas de una economía comercial, estarán menos dispuestos a participar. Si quienes trabajan en la economía comercial comienzan a considerarla una economía de compartición, pueden reducir su atención hacia las recompensas económicas. Por tanto, el mantenimiento de la separación conceptual es clave para sustentar el valor de lo híbrido (Lessig, 2012: 217-218).

Actualmente podemos encontrarnos con que, reconociendo el éxito de este modelo, algunas compañías están tratando, de generar sus propios híbridos o de canalizar la actividad de los fans dentro de modelos de negocio híbridos, sobre todo desde las llamadas industrias culturales, dada la crisis de su modelo de negocio que ha causado -entre otras cosas, pero mayoritariamente- la irrupción de las nuevas tecnologías y, 
en concreto, la digitalización e internet. De esta manera, algo que surgió de forma espontanea, y cuya pervivencia dependía de factores difícilmente controlables, como la voluntad de un grupo de personas interactuando, muchas veces ocultas detrás de un apodo, en foros en internet, ha pasado a querer ser reproducido con objetivos, si bien, no en todos los casos directamente monetarios, encaminados a generar valor de algún tipo para esas compañías.

De esta forma, se tercia indispensable analizar las características que un híbrido de este tipo ha de tener, cuestión que abordaremos estudiando uno de los híbridos que el mismo Lessig ha señalado como válido, la página web ninremixes.com. Al respecto Lessig, en una entrevista realizada dentro de la Free Culture Conference de $2008^{3}$ comenta:

Piensen en dos tipos de híbridos: uno que llamaremos el híbrido Darth Vader. George Lucas tiene un sitio de remezclas para Star Wars. Puedes ir allí y usar fragmentos de vídeo de las películas de Star Wars y subir tu música y remezclarlo. Básicamente ellos tienen esta franquicia de 30 años de antigüedad, y están intentando hacerla interesante de nuevo, así que le dan a los chicos la oportunidad de remezclar el material. Pero si lees los términos de servicio, George Lucas es propietario de todos los derechos de remezcla, le pertenece todo lo que tú creas. Si subes una canción al sitio, él tiene derechos mundiales perpetuos para vender esa canción y ganar el dinero que quiera sin darte un céntimo. Es una especie de aparcería de la era digital. De modo que éste es un tipo de híbrido. Mi punto de vista es que ese tipo de híbrido va a desaparecer, la gente cada vez más va a decir-discúlpenme si hay alguien aquí que le parezca inapropiado-que te jodan con esa clase de híbrido. Esa es la respuesta apropiada. Pero también hay otros híbridos, piensen en Nine Inch Nails o en Girl Talk, que están publicando contenidos, animando expresamente a la gente a que haga cosas con ello, licenciando de manera explícita para que se haga, y licenciándolo de una forma que garantiza que el creador es el propietario de los derechos. No son propietarios del material de Girl Talk, no lo son del material de Nine Inch Nails, pero son propietarios de sus remezclas. Ellos son creadores, este es el derecho de los creadores y espero que este tipo de relación híbrida luche para asegurarse de que sea la que defina el futuro" Transcripción de Bunsnip.com, traducción de José Mesa http:// liferfe.blogspot.com.es/2008/12/conferencia-cultura-libre-2008-berkeley_01.html

Así, uno de los puntos en los que Lessig hace más hincapié a la hora de valorar un híbrido, es en que aquellos que aportan algo al mismo tengan derechos sobre esa aportación. Es decir, que se reconozca, en consonancia con un sistema jurídico que intenta alentar la creación mediante la concesión de derechos de propiedad intelectual, el valor de lo aportado por los creadores no profesionales, el valor y la necesidad de la cultura amateur. Éste, el reconocimiento de las aportaciones, será uno de los pilares del modelo híbrido al que venimos refiriéndonos.

De este modo, en ninremixes.com el usuario puede escuchar la música que alberga la página libremente, puede descargarse las pistas musicales que conforman cada canción y modificarlas de la forma que quiera; incluir pistas de otras canciones disponibles en la web, así como utilizar nuevas pistas de música generada por él mismo, o de las que ostente los derechos apropiados, para dar lugar a una obra derivada. El remezclador sólo tiene permiso para usar las pistas, así, puede someterlas 
al tratamiento musical que considere, y el resultado de ese tratamiento será de su titularidad, pero no puede hacer un uso comercial de las mismas, estén éstas modificadas o no, puesto que al incluir música de la que no tiene permiso para este tipo de uso, esa limitación se extiende a la nueva obra. Es lo que se llama una licencia robusta o copyleft (VVAA, 2012: 29-31). Es decir, Trent Reznor no ostentará derecho alguno sobre la remezcla, no podrá hacer nada con ella, como ocurría en el caso de la página de remezclas de Star Wars mencionado por Lessig, puesto que la obra pertenece al remezclador, pero éste no podrá explotarla comercialmente porque al utilizar las pistas de las canciones de Reznor, ha asumido ese compromiso expresado en la licencia que regula el acceso a las mismas. Por último, si se quiere compartir la nueva remezcla en la página web, se acepta que las pistas que componen la canción también estén disponibles para poder ser utilizadas libremente en las mismas condiciones. Ésta es una forma de asegurar la vitalidad de la comunidad de remezcladores y el que aquellos que se benefician del material colgado en la página web aporten también algo a la misma. Así, la actividad de la mencionada comunidad en el momento de realizar este estudio, se puede resumir en las siguientes cifras, que dan testimonio de su vigor durante un determinado periodo de tiempo: $5.119 \mathrm{mp} 3$ disponibles, 1.818.143 descargas de los ficheros de audio, 72.213 calificaciones en forma de apreciaciones y 151.784 comentarios $^{4}$.

El elemento comparticional del sitio está claro. Los usuarios que comparten sus mezclas en la web no pueden tener una motivación comercial, de acuerdo con los términos de la misma. La hibridación con la economía comercial se comprende si atendemos al propio contexto en el que surge la comunidad de remezcladores. Trent Reznor es un músico profesional, que ha vendido millones de discos y ganado un premio Oscar por la banda sonora de la película The Social Network ${ }^{5}$, pero de forma paralela a sus actividades puramente comerciales, también ha dejado patente en numerosas ocasiones su preocupación por investigar formas alternativas de dar a conocer su música, lo que le ha llevado a disponer varios de sus discos para su libre y gratuita descarga, lanzar un videojuego gratuito online, y también a apadrinar el proyecto que nos ocupa. Puesto que, aunque la gestión de la página web es realizada por voluntarios, el material sobre el que se realizan las remezclas ha sido cedido por Reznor en un patente intento de encontrar nuevos canales para relacionarse con los seguidores de su música. Cómo indica Steven C. Brown en su estudio sobre la relación de Reznor con los fans:

In the case of Nine Inch Nails, at least in the period under scrutiny, exposure to music appears to significantly impact ticket sales; where historically live music has been used to promote sales of hard copies [...]. This relationship now seems to have reversed, with this notion better demonstrated in lieu of the release of free samplers to fans to down load [...]. This new way of connecting with fans ultimately arms them with a reason to buy concert tickets where Holt argues that artists consider recordings less a revenue stream than a publicity tool for touring (2011:202)

Así, podemos entender la página web ninremixes.com -aunque no sólo- como una manera más de promover las venta de entradas para conciertos y otras acciones comerciales de diferente entidad, y es de esta manera como la web se nos muestra 
como un híbrido, y además, un híbrido bien construido, como vimos, según Lessig, puesto que produce beneficios comerciales de la forma indicada, a la par que sostiene las actividades de la comunidad de remezcladores no remunerados. Es decir, mantiene un equilibrio adecuado entre los dos modelos de economía, comercial y de compartición.

De esta forma, podemos extraer de lo apuntado acerca de la página web, y asumiendo en buena parte los principios de la wikinomia (economía wiki) de Tapscott y Williams ${ }^{6}$, una serie de características que pueden funcionar como guía para construir un híbrido coherente:

- Apertura: libre acceso a la información y a su uso.

- Interacción entre iguales: todos los usuarios ostentan los mismos derechos cuando se relacionan entre ellos, lo que implica una estructura social basada en la igualdad y en la transparencia. Los usuarios serán propietarios de sus creaciones, aunque las compartan con la comunidad. En ningún caso nadie se apropiará del trabajo de otro ostentando derechos de propiedad, es en ese sentido en el que debemos entender la igualdad aquí.

- Compartición: es decir, que las compensaciones económicas por las aportaciones a la comunidad quedan excluidas.

- Beneficio comercial: El híbrido debe reportar un beneficio comercial que no ponga en peligro ninguna de las características anteriores.

Por supuesto, estas características no se deben entender como normas, son sólo observaciones extraídas de la forma en que funcionan algunos híbridos de éxito, que pueden servir como marco de referencia, o como sugerencias para aquellos que quieran desenvolverse dentro de esta economía híbrida. Así, muchas compañías (Microsoft, Sun Microsystems, Warner, etcétera) han o están intentando, con mayor o menor fortuna, insertar en sus estructuras híbridos de este tipo, ya sea creándolos ellas o canalizando la actividad de grupos que desarrollan actividades relacionadas con sus productos y servicios. Esas compañías han entendido que aprovechando todas las potencialidades que las nuevas tecnologías de la comunicación (la web 2.0, las redes sociales, las wikis, etcétera) les ofrecen para cooperar con la comunidad de seguidores de esos productos, pueden obtener beneficios sin que el consumidor se sienta agredido, sino todo lo contrario, incluyéndolo, en cierto sentido, en las actividades de la compañía, aunque ello implique relajar -irremediablemente si quieren aprovecharlas de verdad- el control de los derechos sobre sus productos con el objetivo de que esa cooperación no sea mucho más beneficiosa para la compañía que para el fan, lo que podría hacer que éste llegara a replantearse su posición en la misma. De esta forma, se nos muestra claramente la posibilidad de una mayor fidelización del, ya no sólo, consumidor ${ }^{7}$, que siempre tendrá consecuencias positivas, incluso como elemento que incite a la compra de productos que se podrían descargar gratuitamente de internet, como indican Nuttal et al: 
Their affiliation to particular artists and the influence this had on their decision to legally purchase an album because they 'owe it' to the artist (2011, p. 156).

Así, el punto clave será aprovechar bien esas potencialidades, las posibilidades de cooperación y compartición de información que internet ofrece, proporcionando las condiciones suficientes para generar una comunidad, o canalizando de la forma adecuada las comunidades ya existentes. Entonces, deberemos responder a la siguiente cuestión, ¿cómo se construye o mantiene dicha comunidad? Muchas de las recomendaciones de Lessig ya las hemos ido resaltando: libertad para crear y distribuir contenido, sentimiento de pertenencia, reconociendo las aportaciones y permitiendo que la comunidad controle el híbrido mediante la posibilidad de editar su contenido conjuntamente, y una injerencia de la economía comercial que no desvirtúe el sentido de la comunidad, ni la forma de comunicarse y relacionarse de sus miembros. Es decir, la clave estaría en ofrecer o mantener algo que aporte valor a los usuarios, aunque no sea monetario, sin exigirles una contraprestación excesiva a cambio. Una plataforma, centrándonos en internet, que no sólo les reclame sus aportaciones (sus remixes, sus textos, sus fotografías, etcétera), sino que les aporte también algo tal como la posibilidad de comunicarse con otras personas con sus mismos intereses, de exponer sus creaciones a la crítica de una comunidad, o de acceder a herramientas para desarrollar esos intereses, antes de difícil acceso. En palabras de Lessig:

Se crea valor dándole a la gente lo que quiere; se produce algo bueno diseñando lo que ofreces de tal modo que la gente que recibe lo que quiere también devuelva algo a la comunidad. Nadie construye híbridos sobre la base del sacrificio de la comunidad. El valor de dichos híbridos proviene de dar a los miembros de la comunidad lo que quieren de modo que estos también den a la comunidad algo que necesita. La parte vieja de esta historia es que en un mercado competitivo, el éxito proviene de satisfacer las demandas de los consumidores; la parte nueva consiste en reconocer una gama más amplia de deseos, algunos individualistas y otros altruistas, así como la tecnología que puede contribuir a satisfacerlos (2012: 267).

\section{Conflictos y conclusiones}

Después de lo expuesto, podemos concluir que la cuestión del equilibrio entre las dos economías es el elemento esencial, a la par de conflictivo, en el modelo de economía híbrida propuesto por Lessig. Por una parte, las páginas web que albergan esas comunidades necesitan, por lo menos, unos mínimos ingresos para sostenerse (cómo en el caso de ninremixes.com, cuya continuidad peligra por falta de fondos para mantener el sitio web), pero por otra, aquellos que contribuyen a la economía de compartición dentro del híbrido pueden comenzar a preguntarse acerca de la forma en que su trabajo voluntario es explotado por otros. Encontrar el equilibrio es una cuestión compleja, pero como última pincelada, no hay que olvidar que cualquier solución tiene que tener en cuenta que la identidad en la sociedad red pasa de ser una cuestión de pertenencia a un grupo, a ser un proceso reflexivo de construcción que se sedimenta en la actividad social desplegada en la red (Castells, 2005), y que en 
el caso del tipo de grupos que estamos examinando, ésta se concreta en un modelo lúdico, comunitario y exploratorio de creación del conocimiento (Contreras, 2004). Es decir, que la estructura del híbrido debe respetar, en todo caso, el proceso identitario - múltiple, continuo, variable, cambiante- del 'comunero', que aquí se manifestará en la capacidad del mismo para compartir información (entendida en un sentido amplio como datos, sentimientos u opiniones), mezclarla, comentarla, reutilizarla, etcétera. Ese proceso comparticional, como hemos visto, estará regido por una serie de reglas - por una racionalidad intrínseca a todo acto de comunicación entendido de forma abstracta, siguiendo otra vez a Habermas-, que se concretan en la búsqueda del entendimiento mediante el planteamiento de ciertas pretensiones determinadas por el objetivo de la acción comunicativa $-\mathrm{y}$ de la comunidad en nuestro caso-, y en la posibilidad de argumentar nuestros actos comunicativos para defender esas pretensiones. Así, según el objetivo de la comunidad, las pretensiones pueden ser de distinto orden, pero en todo caso, determinan la esencia de la misma, y si se irrumpe en ella de tal forma que se impide que sus miembros se relacionen en estos términos, es decir, si se impide el desarrollo de ese modelo exploratorio y comunitario de creación de conocimiento, se corre el riesgo de que los participantes en el híbrido dejen de identificarse con él, lo que supondría su fracaso.

\section{Bibliografía}

BENKLER, Y. (2005). "Sharing Nicely. On Shareable Goods and the Emergence of Sharing as Modality of Economic Production”. En: Yale Law Journal, volume 114, issue 2, New Haven: Yale Law School, p. 273-358.

BROWN, S. C. (2011). "Artist Autonomy in a Digital Era: The Case of Nine Inch Nails". En: Empirical Musicology Review, vol. 6, n 4, Columbus: Ohio State University Libraries, p. 198-213.

CARABANTE MUNTADA, J. M. (2011). "La teoría discursiva del Derecho de Jurgen Habermas como paradigma para la ciencia del Derecho". En Foro, nueva época, núm. 13, Madrid: Universidad Complutense de Madrid, p. 203-225.

CASTELLS, M. (2005). La era de la información, Vol. 1. Economía, sociedad y cultura. La sociedad red. Madrid: Alianza Editorial.

CONTRERAS, P. (2004). Me llamo Kohfam. Una aproximación antropológica a la identidad hacker. Gedisa: Barcelona.

HABERMAS, J. (1988). La lógica de las ciencias sociales. Madrid: Tecnos.

HABERMAS, J. (2010). Teoría de la acción comunicativa. Madrid: Trotta.

JENKINS, H. (2008). Convergence Culture. La cultura de la convergencia en los medios de comunicación. Barcelona:Paidós.

LESSIG, L. (2012): Remix. Cultura de la remezcla y derechos de autor en el entorno digital. Madrid: Icaría.

NUTALL, P., ARNOLD, S., CARLESS, L., CROCKFORD, L., FINNAMORE, K., FRAZIER, R., y HILL, A. (2011). "Understanding Music Consumption Through 
a Tribal Lens". En: Journal of Retail and Consumer Services, Vol. 18. Bath: University of Bath, p. 152 - 159.

TAPSCOTT, D. y WILLIAMS, A. D. (2007). Wikinomics. La nueva economía de las multitudes inteligentes. Barcelona: Paidós.

VVAA (2012): Copyleft. Manual de uso. Madrid: Traficantes de Sueños.

7.1 Páginas web:

Conferencia Cultura Libre 2008. Berkeley. Lawrence Lessig. Disponible en http:// liferfe.blogspot.com.es/2008/12/conferencia-cultura-libre-2008-berkeley_01. html Consultado el 13 de septiembre de 2013.

\section{Notas}

1 Penguin Books, Londres, existe traducción al español (2012) Remix. Cultura de la remezcla y derechos de autor en el entorno digital, Icaría, Barcelona. Todas citas de esta obra en el artículo serán de la edición española mencionada en esta nota.

2 HABERMAS, Jurgen (2010): Teoría de la acción comunicativa, Trotta Madrid.

3 Organizada por Students for Free Culture, ahora Free Culture Organization: http://freeculture.org/

4 Datos recogidos el 14 de octubre de 2013.

5 La red social en España. Dirigida por David Fincher y estrenada en 2011, narra la historia de la red social Facebook.

6 Apertura, interacción entre iguales, compartición y actuación global (TAPSCOTT y WILLIAMS, 2007: 62)

7 Como apunta Henry Jenkins: "Más que hablar de productores y consumidores mediáticos como si desempeñaran roles separados, podríamos verlos hoy como participantes que interaccionan conforme a un nuevo conjunto de reglas que ninguno de los dos comprende del todo" (Jenkins 2008, p. 15)

\section{Los autores}

María Vanessa García Guardia es diseñadora gráfica, licenciada en Psicología en la Universidad Nacional de Educación a Distancia, y doctoranda en la Facultad de Ciencias de la Información de la Universidad Complutense de Madrid en el programa Técnicas y Procesos de Creación de Imágenes. Autora de varios artículos científicos y conferenciante en varios Seminarios y Congresos, sus líneas de investigación versan sobre estética y psicología y comunicación.

Rafael Timón Gómez es licenciado en Derecho en la Universidad Carlos III de Madrid y doctorando en la Facultad de Ciencias de la Información de la Universidad Complutense de Madrid en el programa Técnicas y Procesos de Creación de Imágenes. Autor de varios artículos científicos y conferenciante en varios Seminarios y 
Congresos, sus líneas de investigación versan sobre sociología de la comunicación, cultura y comunicación y nuevas tecnologías. 